\title{
Dental care and treatments provided under general anaesthesia in the Helsinki Public Dental Service
}

Nora Savanheimo ${ }^{1,2}$, Sari A Sundberg ${ }^{1,2}$, Jorma I Virtanen ${ }^{3,4^{*}}$ and Miira M Vehkalahti ${ }^{1,3}$

\begin{abstract}
Background: Dental general anaesthesia (DGA) is a very efficient treatment modality, but is considered only in the last resort because of the risks posed by general anaesthesia to patients' overall health. Health services and their treatment policies regarding DGA vary from country to country. The aims of this work were to determine the reasons for DGA in the Helsinki Public Dental Service (PDS) and to assess the role of patient characteristics in the variation in reasons and in the treatments given with special focus on preventive care.

Methods: The data covered all DGA patients treated in the PDS in Helsinki in 2010. The data were collected from patient documents and included personal background: age $(<6,6-12,13-17,18-68)$, gender, immigration, previous conscious sedation and previous DGA; medical background; reasons for DGA and treatments provided. Chi-square tests, Fisher's exact test, and logistic regression modelling were employed in the statistical analyses.

Results: The DGA patients ( $n=349$ ) were aged 2.3 to 67.2 years. Immigrants predominated in the youngest age group $(p<0.001)$ and medically compromised patients among the adults $(p<0.001)$ relative to the other age groups. The main reason for DGA was extreme non-cooperation (65\%) followed by dental fear (37\%) and an excessive need for treatment (26\%). In total, 3435 treatments were performed under DGA, 57\% of which were restorations, 24\% tooth extractions, 5\% preventive measures, 5\% radiography, 4\% endodontics and the remaining 5\% periodontics, surgical procedures and miscellaneous. The reasons for DGA and the treatments provided varied according to age, immigration, previous sedation and DGA and medical background. The logistic regression model showed that previous sedation (OR 2.3; 95\% Cl 1.3-4.1; $\mathrm{p}=0.005)$ and extreme non-cooperation ( $\mathrm{OR} 1.7 ; 95 \% \mathrm{Cl}$ 0.9-3.2; $\mathrm{p}=0.103)$ were most indicative of preventive measures given.
\end{abstract}

Conclusions: Extreme non-cooperation, dental fear and an excessive need for treatment were the main reasons for the use of comprehensive, conservative DGA in the Helsinki PDS. The reasons for the use of DGA and the treatments provided varied according to personal and medical background, and immigration status with no gender-differences. Preventive measures formed only a minor part of the dental care given under DGA.

Keywords: Dental general anaesthesia, Public Dental Service, Indications, Comprehensive treatment, Preventive treatment, Immigration, Medically compromised patients

\footnotetext{
* Correspondence: jorma.virtanen@oulu.fi

${ }^{3}$ Department of Community Dentistry, Institute of Dentistry, University of

Oulu, P.O. BOX 5281, Fl-90014 Oulu, Finland

${ }^{4}$ Oulu University Hospital, FI-90220 Oulu, Finland

Full list of author information is available at the end of the article
}

\section{Biomed Central}

(c) 2012 Savanheimo et al.; licensee BioMed Central Ltd. This is an Open Access article distributed under the terms of the Creative Commons Attribution License (http://creativecommons.org/licenses/by/2.0), which permits unrestricted use, distribution, and reproduction in any medium, provided the original work is properly cited. 


\section{Background}

Dental general anaesthesia (DGA) is a very efficient treatment modality, because it only takes a single appointment and requires little or no cooperation on the part of the patient. It is nevertheless considered only in the last resort, because general anaesthesia may pose risks for the patient's overall health. General anaesthesia in early childhood has been reported to affect the child's neurodevelopment, although contradictory findings have been reported $[1,2]$.

The American Academy of Pediatric Dentistry (AAPD) has stated indications for DGA in children and adolescents as follows: (a) patients who cannot cooperate due to a lack of psychological or emotional maturity and/or mental, physical, or medical disability, (b) patients for whom local anaesthesia is ineffective because of acute infection, anatomical variations, or allergy, (c) patients who are extremely uncooperative, fearful, anxious, or uncommunicative, (d) patients who require significant surgical procedures or immediate, comprehensive oral/ dental care and (e) patients for whom the use of DGA may protect the developing psyche and/or reduce the medical risk [3].

The AAPD and the Special Care Dentistry Association (SCDA) both emphasize that dentists should consider other techniques as alternatives to DGA and should use preventive care in order to find best treatment modality and achieve good results in the long term [3-5].

In Finland dental services are provided in both the public and the private sector, the entire population being entitled to Public Dental Service (PDS). Dental care for patients under 18 years of age is free of charge and nearly all children and adolescents receive PDS treatment. In Helsinki, DGA is provided by the PDS for ASA (American Society of Anesthesiologist) grade I-II patients, whereas ASA grade III-IV patients are referred to university hospitals. Conscious sedation is widely used when treating patients with difficulties in dental care, so that only those patients whose treatment would otherwise be very difficult are referred for out-patient DGA. At a consultation appointment preceding the treatment, a dentist specialised in DGA assesses, each patient individually in terms of the treatment options and needs, including proper instructions on oral selfcare and dietary advice. Thus DGA is regarded as a comprehensive process, with preventive care included as one part.

In addition to the AAPD indications, the Helsinki PDS indications for the use of DGA with children and adolescents also recommend this approach for adolescents who are at risk of alienation from society due to dental problems and the need for extensive dental treatment and for adults with intellectual, physical, mental or medical disabilities that could be overcome this way.
The aims of this work were to determine the reasons for DGA in the Helsinki PDS and to assess the role of patient characteristics in the variation in reasons and in the treatments given with special focus on preventive care.

\section{Methods}

\section{Subjects}

The data covered all patients treated under DGA in the PDS in Helsinki, the capital of Finland, in 2010. The data were collected from patient referrals and other documents. Four patients were treated under DGA twice during the year and one patient three times. In these cases the multiple treatments were combined to represent one appointment. Complete documentation was available for every DGA patient.

The personal background data covered age to an accuracy of one month, gender, whether the individual was an immigrant or not, and the history of previous conscious sedation and/or DGA. Age was categorized in the analyses into four classes: $<6,6-12,13-17$ and 18-68 years, the first three describing eruptional stages in the dentition [6] and the fourth the age when patient started to pay medical fees. Immigrant status was defined in terms of nationality or native language.

\section{Medical background}

The medical background data were extracted from the free format text contained in the patient documents and referrals. Medically compromised patients were recorded under five headings, allowing multiple records to be kept per patient: (a) intellectual disability, (b) behavioural disorders, (c) mental disorders, (d) physical limitations such as diseases of the nervous system or senses or musculoskeletal or connective tissue, and (e) other chronic medical conditions such as endocrine, nutritional, metabolic, infectious, circulatory, cardiac, digestive or respiratory system diseases. Allergies and surgical operations were not recorded. Medically compromised patients were categorized as having intellectual only $(\mathrm{a}+\mathrm{b}+\mathrm{c})$, physical only $(\mathrm{d}+\mathrm{e})$, or both types of compromising conditions. For further analyses the patient's medical background was dichotomized as having or not having any medically compromised conditions.

\section{Reasons for DGA}

At the consultation appointment a DGA dentist assesses one or more reasons for treatment under DGA for each patient. The reasons were categorized for the present purpose as: extreme non-cooperation, extreme dental fear, an excessive need for treatment, avoidance of dental fear (for very young patients with no previous treatment experiences), large surgical procedures, a strong emetic reflex or ineffectiveness of local anaesthesia. Multiple reasons were allowed. 


\section{Treatments under DGA}

The data on the dental treatments performed under DGA were based on the patients' documents. We recorded the number of restorations (including stainless steel crowns), extractions and endodontics (pulpotomies and root canal treatments) and surgical treatments (included surgical extractions, lingual and labial frenectomies, surgical removal of cystic lesions, buccal exostosis, odontoma and benign lesions in the oral soft tissue, tooth exposures, autotransplantations, placing of Bollard plates, excisions of hyperplastic tissue and cleaning of the incisive canal). Prophylaxis included professional tooth cleaning and/or topical application of chlorhexidine or fluoride. In addition, fissure sealants, periodontal therapy and radiographs taken during DGA were recorded separately. Prophylaxis and fissure sealants were combined under the heading of prevention. Miscellaneous treatments included alginate and precision impressions, adjustment of occlusal appliances, immediate complete dentures and Schwartz plates, repair of periodontal splints and other minor procedures.

\section{Ethical consideration}

The ethics committee at the City of Helsinki Health Centre approved the study and granted full permission for it. Individuals were labelled with consecutive numbers for identification in the data analyses.

\section{Statistical analyses}

The statistical analyses employed Chi-square tests, Fisher's exact test, and logistic regression modelling.

\section{Results}

\section{Description of patients}

A total of 349 patients (185 male and 164 female) were treated under DGA in the Helsinki PDS in 2010. Their ages ranged from 2.3 to 67.2 years, with $31 \%$ under 6 years of age, 35\% aged 6 to 12, 9\% aged 13 to 17 and $25 \%$ aged 18 years or over (Table 1 ).

The patients' characteristics are shown by age groups in Table 1. Immigrants predominated in the youngest age group, $51 \%$ compared with $25 \%$ in the $6-12$-yearolds and $7-8 \%$ in the older groups $(\mathrm{p}<0.001)$. Of all the DGA patients $54 \%$ had previously received conscious sedation for dental care, with no age difference, whereas previous DGA was more frequent among the older patients $(\mathrm{p}<0.001)$.

Medically compromised patients predominated among the adults, $86 \%$, whereas the vast majority of the $0-5-$ year-old (88\%) and 6-12-year-old (76\%) DGA-patients $(\mathrm{p}<0.001)$ had no medically compromising conditions. The mean proportion of all the DGA patients having one or more medically compromising conditions was $39 \%$ consisting of $14 \%$ intellectual conditions, $10 \%$ physical, and of $15 \%$ both. All three categories became more frequent the older the patients were $(\mathrm{p}<0.001)$.

\section{Reasons for DGA}

The patient documentation revealed an average of 1.5 reasons for DGA per patient, 54\% having one reason, $40 \%$ two and 6\% three. Among the adult patients $73 \%$ had one reason for DGA, as compared with $48 \%$ and $49 \%$ in the two youngest age groups $(\mathrm{p}=0.002)$.

Table 1 Description of the patients $(n=349)$ treated under dental general anaesthesia (DGA), by age group

\begin{tabular}{|c|c|c|c|c|c|c|}
\hline $\begin{array}{l}\text { Characteristics } \\
\text { of patients }\end{array}$ & $\frac{\text { Total }}{\mathrm{n}=349, \%}$ & $\frac{0-5 y r}{n=108, \%}$ & $\frac{6-12 y r}{n=123, \%}$ & $\frac{13-17 y r}{n=30, \%}$ & $\frac{18-68 \mathrm{yr}}{\mathrm{n}=88, \%}$ & $p$ \\
\hline \multicolumn{7}{|l|}{ Gender } \\
\hline Male & 53 & 55 & 52 & 43 & 56 & 0.673 \\
\hline Female & 47 & 45 & 48 & 57 & 44 & \\
\hline \multicolumn{7}{|l|}{ Immigrant } \\
\hline Yes & 27 & 51 & 25 & 7 & 8 & $<0.001$ \\
\hline No & 73 & 49 & 75 & 93 & 92 & \\
\hline \multicolumn{7}{|l|}{ Previous sedation } \\
\hline Yes & 54 & 50 & 55 & 43 & 60 & 0.318 \\
\hline No & 46 & 50 & 45 & 57 & 40 & \\
\hline \multicolumn{7}{|l|}{ Previous DGA } \\
\hline Yes & 20 & 1 & 14 & 37 & 48 & $<0.001$ \\
\hline No & 80 & 99 & 86 & 63 & 52 & \\
\hline \multicolumn{7}{|c|}{ Medically compromised } \\
\hline Yes & 39 & 12 & 24 & 63 & 86 & $<0.001$ \\
\hline No & 61 & 88 & 76 & 37 & 14 & \\
\hline
\end{tabular}

Statistical evaluation by chi-square tests for differences by age group. 
Table 2 Reasons for dental general anaesthesia (DGA), by age group

\begin{tabular}{|c|c|c|c|c|c|c|}
\hline Reasons for DGA & $\frac{\text { Total }}{\mathrm{n}=349, \%}$ & $\frac{0-5 y r}{n=108, \%}$ & $\frac{6-12 y r}{n=123, \%}$ & $\frac{13-17 y r}{n=30, \%}$ & $\frac{18-68 \mathrm{yr}}{\mathrm{n}=88, \%}$ & $p$ \\
\hline Extreme non-cooperation & 65 & 75 & 65 & 60 & 55 & 0.025 \\
\hline Extreme dental fear & 37 & 21 & 43 & 60 & 40 & $<0.001$ \\
\hline Excessive need for treatment & 26 & 35 & 27 & 33 & 11 & 0.002 \\
\hline Avoidance of dental fear & 10 & 27 & 5 & 0 & 0 & $<0.001 \mathrm{~F}$ \\
\hline Large surgical procedures & 7 & 2 & 14 & 7 & 5 & $0.003 \mathrm{~F}$ \\
\hline Strong emetic reflex & 6 & 1 & 5 & 0 & 15 & $<0.001 \mathrm{~F}$ \\
\hline Ineffectiveness of local anesthesia & 1 & 0 & 1 & 3 & 3 & $0.100 \mathrm{~F}$ \\
\hline
\end{tabular}

For each patient, one or more reasons for referring to DGA were documented.

Statistical evaluation by chi-square tests for differences by age group. F=Fisher's exact test $(F)$ applied.

The reasons for DGA by age of the patients are shown in Table 2. The main reason was extreme noncooperation (65\%) followed by extreme dental fear (37\%) and an excessive need for treatment (26\%). This rank order was the same for all age groups except the youngest one, where avoidance of dental fear was the reason in $27 \%$ of cases and for 18-68 year-olds, where a strong emetic reflex was the reason for $15 \%$ of cases. Age was a powerful determinant for most of the reasons, but no gender-differences were found.

The three most common reasons for treatment under DGA are shown in relation to the patients' characteristics in Table 3. An immigrant background was more often indicative of an excessive need for treatment than a non-immigrant one ( $37 \%$ vs. $22 \%$; $=0.005)$ and was less often indicative of a dental fear ( $27 \%$ vs. $41 \%$; $\mathrm{p}=0.023)$. Those with previous experience of sedation more often showed extreme non-cooperation and dental fear than their non-sedated counterparts but less often had an excessive need for treatment. Likewise an excessive need for treatment was less frequent for those with previous DGA and/or medically compromising condition, than for those with no previous DGA (10\% vs. $30 \%$; $\mathrm{p}<0.001)$ or with no medical problems $(18 \%$ vs. $31 \%$; $\mathrm{p}=0.007)$.

\section{Treatments under DGA}

A total of 3435 treatments were performed under DGA, of which $57 \%$ were restorations, $24 \%$ tooth extractions, $5 \%$ preventive measures, $5 \%$ radiography and $4 \%$ endodontics, the remaining $5 \%$ being periodontics, surgical procedures and miscellaneous. The mean number of treatments per patient was 9.8 (SD 5.0), ranging from 8.8 (SD 3.9) for 6-12-year-olds to 11.0 (SD 5.6) for 1317-year-olds. Most of the treatments were restorations (5.6, SD 3.6) and extractions (2.3, SD 3.3).

The percentages of patients who received each type of treatment are presented by age in Figure 1. The youngest age group dominated those receiving filling therapy (97\% vs. 84-88\%; $\mathrm{p}=0.016)$ and endodontic treatment ( $51 \%$ vs. $15-27 \%$; $<<0.001$ ), the $6-12$-year-olds those receiving preventive treatment $(37 \%$ vs. $10-24 \%$; $\mathrm{p}<0.001)$ and the adults those receiving periodontic treatment (66\% vs. $4-37 \%$; $\mathrm{p}<0.001$ ). Altogether $26 \%$ of the patients had radiographs taken under DGA.

The treatments received under DGA are shown by patient characteristics in Table 4. Being an immigrant pointed to filling therapy and endodontics more often than being a non-immigrant but less to periodontics, while those with previous sedation more often received filling therapy, preventive measures or periodontics than

Table 3 The most common reasons for dental general anaesthesia (DGA), by patient characteristics

\begin{tabular}{|c|c|c|c|c|c|c|c|c|}
\hline \multirow[t]{3}{*}{ Reasons for DGA } & \multicolumn{2}{|c|}{ Immigrant } & \multicolumn{2}{|c|}{ Previous sedation } & \multicolumn{2}{|c|}{ Previous DGA } & \multicolumn{2}{|c|}{ Medically compromised } \\
\hline & Yes & No & Yes & No & Yes & No & Yes & No \\
\hline & $n=95, \%$ & $\mathrm{n}=\mathbf{2 5 4 , \%}$ & $\mathrm{n}=188, \%$ & $\mathrm{n}=161, \%$ & $\mathrm{n}=71, \%$ & $\mathrm{n}=\mathbf{2 7 8 , \%}$ & $\mathrm{n}=137, \%$ & $\mathrm{n}=212, \%$ \\
\hline Extreme non- & 71 & 63 & 79 & 49 & 68 & 64 & 62 & 67 \\
\hline cooperation & $p=0.189$ & & $p<0.001$ & & $p=0.612$ & & $p=0.345$ & \\
\hline Extreme dental & 27 & 41 & 43 & 30 & 31 & 38 & 33 & 40 \\
\hline fear & $p=0.023$ & & $p=0.011$ & & $p=0.242$ & & $p=0.200$ & \\
\hline Excessive need & 37 & 22 & 18 & 35 & 10 & 30 & 18 & 31 \\
\hline for treatment & $p=0.005$ & & $p<0.001$ & & $p<0.001$ & & $p=0.007$ & \\
\hline
\end{tabular}

Statistical evaluation by chi-square tests for differences according to patient characteristics. 


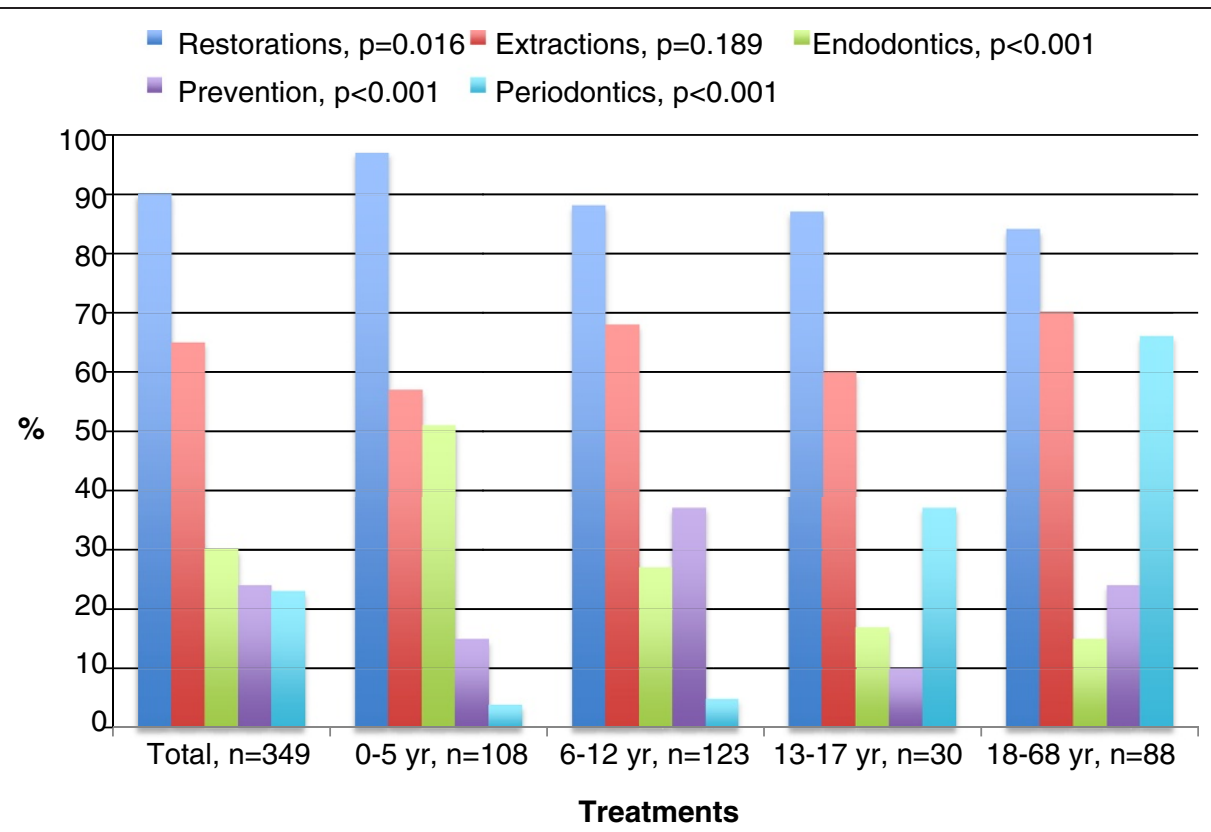

Figure 1 Percentages (\%) of dental general anaesthesia patients $(n=349)$ receiving various treatments, by age group. P-values refer to differences between the age groups.

their non-sedated counterparts and those with previous DGA less often received filling therapy or endodontic treatment but more preventive measures or periodontics. The medically compromised DGA patients received filling therapy and endodontic treatment less often than did those without medical problems, but periodontic treatment more often.

The treatments received by the patients are shown by reasons for DGA in Table 5. Those with extreme noncooperation, extreme dental fear or an excessive need for treatment received filling therapy more often than those without these properties, while endodontic and preventive treatments were more common for those with extreme non-cooperation and tooth extraction and periodontics for those with an excessive need for treatment.

The roles of patient characteristics and the reasons for DGA with regard to the provision of preventive treatment during the DGA session are shown in Table 6. Previous sedation was more frequently indicative of preventive treatment $(\mathrm{OR}=2.3 ; 95 \% \mathrm{Cl} 1.3-4.1 ; \mathrm{p}=0.005)$ and tooth extraction less frequently $(\mathrm{OR}=0.9 ; 95 \% \mathrm{Cl} 0.8$ -

Table 4 Treatments provided for dental general anaesthesia (DGA) patients $(n=349)$ by patient characteristics

\begin{tabular}{|c|c|c|c|c|c|c|c|c|c|}
\hline \multirow[t]{3}{*}{ Treatments received } & \multirow{3}{*}{$\frac{\text { Total }}{n=349, \%}$} & \multicolumn{2}{|c|}{ Immigrant } & \multicolumn{2}{|c|}{ Previous sedation } & \multicolumn{2}{|c|}{ Previous DGA } & \multicolumn{2}{|c|}{ Medically compromised } \\
\hline & & Yes & No & Yes & No & Yes & No & Yes & No \\
\hline & & $n=95, \%$ & $\mathrm{n}=\mathbf{2 5 4 , \%}$ & $\mathrm{n}=188, \%$ & $\mathrm{n}=161, \%$ & $\mathrm{n}=71, \%$ & $\mathrm{n}=\mathbf{2 7 8 , \%}$ & $\mathrm{n}=137, \%$ & $n=212, \%$ \\
\hline Filling & 90 & 100 & 86 & 93 & 86 & 82 & 92 & 85 & 93 \\
\hline \multicolumn{2}{|l|}{ therapy } & \multicolumn{2}{|c|}{$p<0.001$} & \multicolumn{2}{|c|}{$p=0.024$} & \multicolumn{2}{|c|}{$p=0.013$} & \multicolumn{2}{|c|}{$p=0.013$} \\
\hline Tooth & 65 & 66 & 64 & 65 & 64 & 55 & 67 & 66 & 64 \\
\hline extraction & & \multicolumn{2}{|c|}{$p=0.709$} & \multicolumn{2}{|c|}{$p=0.777$} & \multicolumn{2}{|c|}{$p=0.052$} & \multicolumn{2}{|c|}{$p=0.768$} \\
\hline \multirow[t]{2}{*}{ Endodontics } & 30 & 47 & 24 & 29 & 32 & 14 & 35 & 23 & 35 \\
\hline & & \multicolumn{2}{|c|}{$p<0.001$} & \multicolumn{2}{|c|}{$p=0.624$} & \multicolumn{2}{|c|}{$p<0.001$} & \multicolumn{2}{|c|}{$p=0.011$} \\
\hline \multirow[t]{2}{*}{ Prevention } & 24 & 31 & 22 & 32 & 16 & 34 & 22 & 26 & 24 \\
\hline & & \multicolumn{2}{|c|}{$p=0.101$} & \multicolumn{2}{|c|}{$p<0.001$} & \multicolumn{2}{|c|}{$p=0.038$} & \multicolumn{2}{|c|}{$p=0.677$} \\
\hline \multirow[t]{2}{*}{ Periodontics } & 23 & 11 & 27 & 28 & 17 & 51 & 15 & 45 & 8 \\
\hline & & \multicolumn{2}{|c|}{$p<0.001$} & \multicolumn{2}{|c|}{$p=0.015$} & \multicolumn{2}{|c|}{$p<0.001$} & \multicolumn{2}{|c|}{$p<0.001$} \\
\hline
\end{tabular}

Statistical evaluation by chi-square tests for differences according to patient characteristics. 
Table 5 Treatments provided for dental general anaesthesia (DGA) patients $(n=349)$ by reasons for DGA

\begin{tabular}{|c|c|c|c|c|c|c|c|}
\hline \multirow[t]{3}{*}{ Treatments received } & \multirow{3}{*}{$\frac{\text { Total }}{n=349, \%}$} & \multicolumn{2}{|c|}{ Extreme non-cooperation } & \multicolumn{2}{|c|}{ Extreme dental fear } & \multicolumn{2}{|c|}{ Excessive need for treatment } \\
\hline & & Yes & No & Yes & No & Yes & No \\
\hline & & $\mathrm{n}=227, \%$ & $n=122, \%$ & $\overline{n=129, \%}$ & $\overline{n=220, \%}$ & $\mathrm{n}=91, \%$ & $\mathrm{n}=\mathbf{2 5 8 ,} \%$ \\
\hline \multirow[t]{2}{*}{ Filling therapy } & 90 & 94 & 81 & 95 & 86 & 97 & 87 \\
\hline & & \multicolumn{2}{|c|}{$p<0.001$} & \multicolumn{2}{|c|}{$p=0.008$} & \multicolumn{2}{|c|}{$p=0.010$} \\
\hline \multirow[t]{2}{*}{ Tooth extraction } & 65 & 66 & 62 & 70 & 62 & 74 & 62 \\
\hline & & \multicolumn{2}{|c|}{$p=0.480$} & \multicolumn{2}{|c|}{$p=0.134$} & \multicolumn{2}{|c|}{$p=0.039$} \\
\hline \multirow[t]{2}{*}{ Endodontics } & 30 & 34 & 24 & 26 & 33 & 34 & 29 \\
\hline & & \multicolumn{2}{|c|}{$p=0.049$} & \multicolumn{2}{|c|}{$p=0.212$} & \multicolumn{2}{|c|}{$p=0.373$} \\
\hline \multirow[t]{2}{*}{ Prevention } & 24 & 30 & 15 & 19 & 28 & 23 & 25 \\
\hline & & \multicolumn{2}{|c|}{$p=0.002$} & \multicolumn{2}{|c|}{$p=0.055$} & \multicolumn{2}{|c|}{$p=0.741$} \\
\hline \multirow[t]{2}{*}{ Periodontics } & 23 & 24 & 20 & 21 & 24 & 14 & 26 \\
\hline & & \multicolumn{2}{|c|}{$p=0.483$} & \multicolumn{2}{|c|}{$p=0.560$} & \multicolumn{2}{|c|}{$p=0.027$} \\
\hline
\end{tabular}

Statistical evaluation by chi-square tests for differences according to reasons for dental GA.

0.98; $\mathrm{p}=0.022$ ). Extreme non-cooperation tended to be indicative of prevention, whereas extreme dental fear tended to result in less preventive measures.

\section{Discussion}

Extreme non-cooperation and extreme dental fear were the most important factors leading to DGA, and should, therefore be taken into account and prevented early on in order to reduce the need for DGA. The present findings based on a unique body of PDS data covering all age groups support earlier observations that dental fear, non-cooperation, compromising medical conditions and the need for extensive dental treatment are the most common reasons for out-patient DGA [7-12]. From the parents' point of view, dental fear and repeated unpleasant experiences during dental treatment can lead to a utilisation for DGA even in the case of healthy children [13].

One of the commonest among the many reasons lying behind non-cooperation in children is dental fear [14]. It has been reported in Finland that $21-36 \%$ of children are quite afraid or very afraid of something connected with dental treatment [15] and that 5-19\% of adults are very afraid of visiting a dentist [16], while correspondingly one fourth of adults in England reported that they definitely always feel anxious about going to a dentist [17]. Non-cooperative and fearful patients need more time and effort on the part of the dental team. Many of the present patients had previously received dental treatment under conscious sedation, indicating that dentists had tried to treat their dental fear prior to resorting to DGA. As DGA does not diminish dental fear, as reported in children [18], dental fear needs to be dealt with after DGA. Patients in the Helsinki PDS are scheduled for a post-DGA appointment, which simulates a normal dental situation, with the intention of guiding the patient back to normal dental care. In addition, proper oral self-care instructions and dietary advice are provided over again.

DGA in the Helsinki PDS context was a comprehensive, conservative process characterized by a predominance of filling therapy, endodontics and periodontics.

Table 6 Factors explaining the provision of preventive treatment under dental general anaesthesia in logistic regression modelling

\begin{tabular}{|c|c|c|c|c|c|}
\hline Parameter & Estimate & SE & OR & $95 \% \mathrm{Cl}$ & $p$ \\
\hline Being immigrant: $0=\mathrm{No}, 1=$ Yes & 0.469 & 0.31 & 1.6 & $0.9,2.9$ & 0.128 \\
\hline Previous sedation: $0=\mathrm{No}, 1=$ Yes & 0.830 & 0.30 & 2.3 & $1.3,4.1$ & 0.005 \\
\hline Receiving tooth extraction: $0=\mathrm{No}, 1=$ Yes & -0.139 & 0.06 & 0.9 & $0.8,0.98$ & 0.022 \\
\hline Extreme non-cooperation: $0=\mathrm{No}, 1=$ Yes & 0.532 & 0.33 & 1.7 & $0.9,3.2$ & 0.103 \\
\hline Extreme dental fear: $0=\mathrm{No}, 1=$ Yes & -0.473 & 0.30 & 0.6 & $0.3,1.1$ & 0.110 \\
\hline Excessive need for treatment: $0=\mathrm{No}, 1=$ Yes & 0.353 & 0.33 & 1.4 & $0.7,2.7$ & 0.283 \\
\hline Constant term & -1.975 & 0.43 & & & \\
\hline
\end{tabular}


Comprehensive DGA has earlier been reported in many European countries [8,9,11,19-21], North America $[7,22,23]$, the Middle East [24,25], Asia [26,27] and New Zealand [28]. Contradictory findings have recently been reported from Australia and England, where DGA is used primarily for extractions in both children and adults [29-31], although a move towards comprehensive DGA care has also been made in the United Kingdom since the publication of the Royal College of Surgeon's guidelines for the use of GA in paediatric dentistry in 2008 [32].

Nearly one fourth of the patients received preventive treatment under DGA, but the overall proportion of this, $5 \%$ was relatively small. One explanation may be that tooth extractions performed in this way do not allow prophylaxis at the same time. Fissure sealants and prophylaxis have been reported earlier as part of a comprehensive dental care regimen performed under DGA on children $[7,10,11]$, but among our patients nearly one fourth of the adults received preventive treatment, too.

Half of our adult patients had previously been treated under DGA, and $86 \%$ of the adults had a medically compromising condition, indicating that they belonged to a group whose dental care must necessarily be performed under DGA. Dougherty [33] states that the decision as to which treatment modality is in the best interest of a patient with special needs should be made individually, but there is little evidence for what might be the optimal frequency of treatment episodes under DGA.

Our findings were based on patient documents and referrals, which normally include no information about socioeconomic status. Immigration status is noted, however, and may be used as an indication of cultural differences which may affect oral health and related behaviour. The fact that immigrant children were overrepresented among our young DGA patients is in line with an earlier report from Denmark [12]. By contrast, an Australian report states that indigenous children have a higher risk of receiving DGA [19]. To reduce inequalities in the use of health services, the Helsinki PDS has initiated multiprofessional collaboration in a programme that provides information on dental care and prevention for immigrant families and education in cultural disparities for PDS personnel.

City of Helsinki statistics show that around 160000 out of a total of almost 600000 Helsinki residents were treated in the PDS in 2010 and that 349 of these were DGA patients, indicating that DGA is used as a last resort and only when certain strict criteria have been fulfilled. Our comprehensive data on DGA treatments provided during one-year are representative of the situation in the Helsinki PDS and may be generalized for the whole country, since Helsinki residents make up over $10 \%$ of Finland's population. The data were based on the patients' dental documents, the compiling of which is governed by strict rules in Finland.

\section{Conclusions}

Extreme non-cooperation, dental fear and an excessive need for treatment were the main reasons for the use of comprehensive, conservative DGA in the Helsinki PDS. The reasons for the use of DGA and the treatments provided varied according to personal and medical background, and immigration status with no gender-differences. Preventive measures were more frequently performed on patients with previous experience of conscious sedation or extreme non-cooperation, but these measures formed only a minor part of the dental care given under DGA.

\section{Competing interests}

The author(s) declare that they have no competing interests.

\section{Authors' contributions}

NS: designed the study, collected data and wrote the manuscript, SAS: designed the study and collected data, JIV: designed the study and wrote the manuscript, MMV: designed the study, performed statistical analyses and wrote the manuscript. All authors read and approved the final manuscript.

\section{Acknowledgements}

The collaboration of the Oral Health Care Department of City of Helsinki is gratefully acknowledged.

\section{Author details}

${ }^{1}$ Department of Oral Public Health, Institute of Dentistry, University of Helsinki, P.O. BOX 41, FI-00014 Helsinki, Finland. ${ }^{2}$ Oral Health Care Department, City of Helsinki Health Centre, P.O. BOX 6000, 00099 City of Helsinki, Finland. ${ }^{3}$ Department of Community Dentistry, Institute of Dentistry, University of Oulu, P.O. BOX 5281, FI-90014 Oulu, Finland. ${ }^{4}$ Oulu University Hospital, FI-90220 Oulu, Finland.

Received: 12 July 2012 Accepted: 24 October 2012

Published: 27 October 2012

\section{References}

1. Sun L: Early childhood general anaesthesia exposure and neurocognitive development. Br J Anaesth 2010, 105(Suppl 1):i61-i68.

2. Stratmann G: Review article: Neurotoxicity of anesthetic drugs in the developing brain. Anesth Analg 2011, 113:1170-1179.

3. The American Academy of Pediatric Dentistry: Guideline on behavior quidance for the pediatric dental patient:; 2011. http://www.aapd.org.

4. American Academy on Pediatric Dentistry Council on Clinical Affairs: Guideline on management of dental patients with special health care needs. Pediatr Dent 2008-2009, 30(7 Suppl):107-111.

5. Glassman P, Caputo A, Dougherty N, Lyons R, Messieha Z, Miller C, Peltier B, Romer M: Special Care Dentistry Association consensus statement on sedation, anesthesia and alternative techniques for people with special needs. Spec Care Dentist 2009, 29:2-8.

6. Haavikko K: The formation and the alveolar and clinical eruption of the permanent teeth. An orthopantomographic study. University of Helsinki: PhD Thesis; 1970.

7. Legault JV, Diner MH, Auger R: Dental treatment of children in a general anaesthesia clinic: review of 300 cases. J Can Dent Assoc (Tor) 1972, 38:221-224.

8. Grytten J, Holst D, Dyrberg L, Fæhn O: Some characteristics of patients given dental treatment under general anesthesia. Acta Odontol Scand 1989, 47:1-5.

9. Tarján I, Mikecz G, Dénes J: General anaesthesia of out-patients in pedodontics. J Int Assoc Dent Child 1990, 20:59-61. 
10. Nunn JH, Davidson G, Gordon PH, Storrs J: A retrospective review of a service to provide comprehensive dental care under general anesthesia. Spec Care Dentist 1995, 15:97-101.

11. Vinckier F, Gizani S, Declerck D: Comprehensive dental care for children with rampant caries under general anaesthesia. Int J Paediatr Dent 2001, 11:25-32.

12. Haubek D, Fuglsang M, Poulsen S, Rølling I: Dental treatment of children referred to general anaesthesia - association with country of origin and medical status. Int J Paediatr Dent 2006, 16:239-246.

13. Savanheimo N, Vehkalahti MM, Pihakari A, Numminen M: Reasons for and parental satisfaction with children's dental care under general anaesthesia. Int J Paediatr Dent 2005, 15:448-454.

14. Baier K, Milgrom P, Russell S, Mancl L, Yoshida T: Children's fear and behavior in private pediatric dentistry practises. Pediatr Dent 2004, 26:316-321.

15. Rantavuori K: Aspects and determinants of children's dental fear. University of Oulu, Faculty of Medicine, Institute of Dentistry: PhD thesis; 2008.

16. Lahti S, Vehkalahti MM, Nordblad A, Hausen H: Dental fear among population aged 30 and older in Finland. Acta Odontol Scand 2007, 65:97-102.

17. Kelly M, Steele J, Nuttall N, Bradnock G, Morris J, Nunn J, Pine C, Pitts N, Treasure E, White D: Adult Dental Health Survey. Oral Health in the United Kingdom 1998. Office for National Statistics. London: The Stationary Office; 2000.

18. Klaassen MA, Veerkamp JSJ, Hoogstraten J: Young children's Oral HealthRelated Quality of Life and dental fear after treatment under general anaesthesia: a randomized controlled trial. Eur J Oral Sci 2009, $117: 273-278$.

19. Vermeulen M, Vinckier F, Vandenbroucke J: Dental general anesthesia: clinical characteristics of 933 patients. ASDC J Dent Child 1991, 58:27-30.

20. Pohl Y, Filippi A, Geiger G, Kirschner H, Boll M: Dental treatment of handicapped patients using endotracheal anesthesia. Anesth Prog 1996, 43:20-23.

21. Harrison MG, Roberts GJ: Comprehensive dental treatment of healthy and chronically sick children under intubation general anaesthesia during a 5-year period. Br Dent J 1998, 184:503-506.

22. Enger DJ, Mourino AP: A survey of 200 pediatric dental general anesthesia cases. ASDC J Dent Child 1985, 52:36-41.

23. Loyola-Rodriguez JP, Zavala-Alonso V, Gonzalez-Alvarez CL, Juarez-Lopez LA, Patiño-Marin N, Gonzalez CD: Dental treatment under general anesthesia in healthy and medically compromised/developmentally disabled children: a comparative study. J Clin Pediatr Dent 2009, 34:177-182.

24. Ibricevic $\mathrm{H}, \mathrm{Al}$-Jame Q, Honkala S: Pediatric dental procedures under general anesthesia at the Amiri hospital in Kuwait. J Clin Pediatr Dent 2001, 25:337-342.

25. Jamjoom MM, Al-Malik MI, Holt RD, El-Nassry A: Dental treatment under general anaesthesia at a hospital in Jeddah, Saudi Arabia. Int J Paediatr Dent 2001, 11:110-116.

26. Kwok-Tung L, King NM: Retrospective audit of caries management techniques for children under general anesthesia over an 18-year period. J Clin Pediatr Dent 2006, 31:58-62.

27. Lee PY, Chou MY, Chen YL, Chen LP, Wang CJ, Huang WH: Comprehensive dental treatment under general anesthesia in healthy and disabled children. Chang Gung Med J 2009, 32:636-642.

28. Drummond BK, Davidson LE, Williams SM, Moffat SM, Ayers KM: Outcomes two, three and four years after comprehensive care under general anaesthesia. N Z Dent J 2004, 100:32-37.

29. Jamieson LM, Roberts-Thomson KF: Dental general anaesthetic trends among Australian children. BMC Oral Health 2006, 6:16.

30. Jamieson LM, Roberts-Thomson KF: Dental general anaesthetic receipt among Australians aged 15+ years, 1998-1999 to 2004-2005. BMC Oral Health 2008, 8:10.

31. Moles DR, Ashley P: Hospital admissions for dental care in children: England 1997-2006. Br Dent J 2009, 206:E14.
32. Davies C, Harrison M, Roberts G: UK national clinical guidelines in paediatric dentistry: guideline for the use of general anaesthesia (GA) in paediatric dentistry. London: Royal College of Surgeons of England; 2008.

33. Dougherty N: The dental patient with special needs: a review of indications for treatment under general anesthesia. Spec Care Dentist 2009, 29:17-20.

doi:10.1186/1472-6831-12-45

Cite this article as: Savanheimo et al.: Dental care and treatments provided under general anaesthesia in the Helsinki Public Dental Service. BMC Oral Health 2012 12:45.

\section{Submit your next manuscript to BioMed Central and take full advantage of:}

- Convenient online submission

- Thorough peer review

- No space constraints or color figure charges

- Immediate publication on acceptance

- Inclusion in PubMed, CAS, Scopus and Google Scholar

- Research which is freely available for redistribution

Submit your manuscript at www.biomedcentral.com/submit
C) Biomed Central 